\title{
The Economic Impact of a New Type of Ripening Chamber in Traditional Cheese Manufacturing
}

\author{
Nuno Teixeira ${ }^{1}$, Maria Clara Pires ${ }^{2}$, Paulo Ferreira ${ }^{3,4,5, * \mathbb{D}}$, Graça P. Carvalho ${ }^{4}{ }^{\mathbb{C}}$, \\ Rute Santos $^{3,4,6} \mathbb{D}^{\circ}$, Francisco M. Rodrigues ${ }^{4,6} \mathbb{( D )}_{\text {, João Dias }}{ }^{2,7}$, João C. Martins ${ }^{2}$ \\ and José Jasnau Caeiro ${ }^{2}$
}

1 Department of Accounting and Finance, Polytechnic Institute of Setúbal, 2914-503 Setúbal, Portugal; nuno.teixeira@esce.ips.pt

2 Polytechnic Institute of Beja, 7800-295 Beja, Portugal; clara.pires@ipbeja.pt (M.C.P.); joao.dias@ipbeja.pt (J.D.); joao.martins@ipbeja.pt (J.C.M.); j.caeiro@ieee.org (J.J.C.)

3 VALORIZA-Research Centre for Endogenous Resource Valorization, 7300-555 Portalegre, Portugal; rutesantos@ipportalegre.pt

4 Polytechnic Institute of Portalegre, Agrarian School of Elvas, 7350-092 Elvas, Portugal; gpcarvalho@ipportalegre.pt (G.P.C.); fmondragao@ipportalegre.pt (F.M.R.)

5 CEFAGE-UE, IIFA, Universidade de Évora, Largo dos Colegiais 2, 7000 Évora, Portugal

6 MED-Mediterranean Institute for Agriculture, Environment and Development, Núcleo da Mitra, Apartado 94, 7006-554 Évora, Portugal

7 Geobiosciences, Geobiotechnologies and Geoengineering (GeoBioTec), Faculdade de Ciências e Tecnologias, Universidade Nova de Lisboa, 2829-516 Caparica, Portugal

* Correspondence: pferreira@ipportalegre.pt

Received: 21 July 2020; Accepted: 17 August 2020; Published: 18 August 2020

check for updates

\begin{abstract}
A new prototype of a ripening chamber was proposed in the CFD4CHEESE project aiming to evaluate the application of computational fluid dynamics in the optimization of traditional cheeses ripening conditions. With the purpose of evaluating the possible impact on the energy cost of cheese ripening in three Portuguese regions (Setúbal, Évora, and Beja), we demonstrated the potential economic benefits of the prototype. The proposed automation process would imply higher productive efficiency, reducing the consumption of water and electricity. The simple consideration of the reduction of electricity costs is enough to recover the investment needed to have the new ripening chambers, meaning that the investment is economically viable. In addition to the economic impact in firms, which are mostly small and medium firms, our results also contribute to an increase on the sustainable use of natural resources.
\end{abstract}

Keywords: cost reduction; economic impact; ripening chambers; SME competitiveness

\section{Introduction}

Traditional dairy industry is very relevant in the Alentejo region, with an important impact on the specialization and employment profile of the region. It has been stated that livestock rearing conditions, namely diet composition and extensive systems, as well as the manufacturing process and the ripening conditions contribute to the chemical and sensorial characteristics of the cheeses, being responsible for such unique specificity, influencing the buying decisions and appreciation of consumers [1]. Portugal is recognized as a country where traditional economic activities related to agriculture remain important, not only because they are relevant in rural areas but also because it is possible to find several products with recognized quality, with traditional cheeses being one of the examples. From different types of cheese available, made with ewe, cow, goat, or mixed milk, the firmness, organoleptic properties and composition, among other characteristics, vary depending 
on the region of production [2]. The improvement of the production conditions of a given activity is crucial both at the microeconomic level, enhancing the results of the individual firms, but also at a macroeconomic level, potentiating the economic development of the region. The importance of maintaining investments in the economic activities is well documented and is clear for several activities, including investments in traditional manufacturing firms in general [3], but also in the specific case of the dairy industry $[4,5]$. As expected, the investments in this sector in particular have an important relevance on the productivity [6,7], and consequently on the economy as a whole. The investment decisions in the dairy sector could also have relevant impacts on environmental issues, which could contribute to the achievement of the objectives of sustainable development $[8,9]$.

In the last decades, traditional ripening rooms, using empirical knowledge for the control of environmental conditions, have been replaced by modern ripening chambers with automatic control of temperature and humidity. However, the use of refrigeration systems based on the vapor compression cycle are largely responsible for the high energetic costs, that in some enterprises may reach $60 \%$ of the total energetic costs [10]. Within the scope of the "CFD4CHEESE-Application of computational fluid dynamics in the optimization of traditional cheeses ripening conditions" project, new insights were used to improve the environmental conditions in small ripening chambers using computational fluid dynamics but also using remote monitoring and sensing to evaluate operational costs like energy and water consumption. These improvements are expected to increase the quality and efficiency of the cheese produced with raw ewe's milk and thus increase the quantity of cheese granted with protected designation of origin (PDO) status. The efficiency of the production process is also fundamental for the profitability of the activity, since it allows for optimization of the use of raw materials and an increase in the quantities of final product available to the market. It is hence possible to optimize the relationship between inputs and outputs of the activity, this being one of the major concerns of the project. The eventual certification is important because it guarantees producers to have higher economic results in terms of firms [11] but also at a macroeconomic level [12].

The ripening process of the cheeses occurs in specialized chambers, which work under idealized conditions of temperature, humidity, or ventilation, depending on the type of cheese. During the ripening process, biochemical changes occur mainly due to microbiological activity, leading to the development of the differential characteristics of such cheeses in terms of texture, flavor, and aroma [13, 14]. Temperature and humidity are crucial conditions in the process to ensure good production results. In fact, this occurs in a wide variety of cheeses, like Camembert-type [15] or Serra cheese [16]. Moreover, and besides temperature and humidity, even the gas composition of the air presented in the ripening chambers could have an influence over the cheeses, affecting issues like microbial activities and organoleptic features of the product, with consequences in firm productivity and in the quality of the product [17]. The ripening process is a crucial part of the production of the cheese and, when not correctly managed, it implies the possibility of having defective products. A proper traditional ripening process implies a daily task of turning the cheeses one by one, besides the need of washing two to four times per ripening cycle. In most cheese factories, it is also necessary to periodically change the position of the cheeses inside the ripening chamber due to the heterogeneity of the environmental conditions. All these intrinsic features of the ripening process make a high efficiency of the ripening chamber even more important to minimize labor costs and quality loss.

In order to continue to preserve the characteristics of traditional cheeses, different geographic production areas were created in Portugal, in a total of 13 PDOs and one protected geographical indication, including the production areas of Azeitão, Évora, and Serpa, which are under analysis in this paper. In 2015 it was estimated that the cheese sector represented about $25 \%$ of the dairy sector in general, with a sales volume of about 1800 million euros [18]. However, the trade balance (in the cheese category) is quite unbalanced, with a deficit of about 30\% in terms of the national production [18]. Nevertheless, this deficit has been reduced in recent years, since the national industry has made great efforts to strengthen its external competitiveness, through the promotion of its brands and through adaptation to the requirements of various destination markets. 
Although prices remain an important variable, adding some value to the supplied products by obtaining the certification allows for selling to more demanding customer segments in terms of the quality of the final product and price sensitivity. In general, certified cheeses could have a price increase of about $23 \%$ compared to non-certified ones, allowing these companies to have a higher margin to cover their activity expenses [19].

According to the last available data on the database of Central de Balanços do Banco de Portugal [20], a total of 249 firms in the dairy industry corresponded to a total of 5710 employers and about 1.4 billion euros. This is a highly concentrated sector with $20 \%$ of the firms having almost $96 \%$ of the sales. Sales were decreasing from 2013 to 2016 with a slight increase in 2017. The cost of raw materials, mainly milk, is the most important factor (about $69 \%$ of the total) followed by external services (including water and electricity) and human resources.

Despite the importance of national results, information about firms devoted to the production of cheese in the regions under analysis is more relevant for this study. Considering the elements identified in the methodological section, we could identify a total of 46 firms with available data, with a total of 22 firms which could produce cheese of Évora, 16 of Serpa, and eight of Azeitão, most of them with more than 10 years in the market. From the economic analysis it was possible to find the results for a total of 31 firms, once we considered just the ones which presented results from 2015 to 2018. The results are consistent with the general findings of the dairy sector, with an increase of sales and profits in the final sample, and the predominance of the cost with raw materials in the cost structure of the firms, although a lower percentage (about 55\%) with a higher share, in this case, for the external services (about $31 \%$ ). Despite the apparently good financial results, the gross added value was much lower in 2018 than in 2015, which could mean there was some difficulty for the firms to be competitive and some incapacity to differentiate themselves from competitors in general.

The above-mentioned project itself is important because it identifies the structure of a new ripening chamber to be used in traditional cheese manufacturing. Considering those objectives, this work fills the existing gap in the literature because it identifies the economic relevance of the application of those ripening chambers in the real economy. We are interested in analyzing the potential benefits and the potential costs of the new prototype, quantifying them, and directly studying the economic viability of the prototype. Moreover, and for the particular case of the consumption of electricity and water, we are interested in studying the hypothesis that the prototype reduces the consumption of both resources. Our main results show that the investment needed for the automation in the ripening chambers is viable once it creates enough cash flow considering the estimated items of the investment and the reduction in energy costs.

\section{Material and Methods}

To pursue the objectives of the project, we decided firstly to build a questionnaire to make a brief characterization of the firms which produce raw ewe's milk cheese inside the PDO regions of Queijo de Azeitão, Queijo de Évora, and Queijo Serpa. The questionnaire was built from data retrieval, with direct interviews with the managers, in order to collect information about the dimension of the firm, the structure of the costs, or the characteristics of ripening chambers, among other relevant information. In total, we interviewed 28 firms, from the different PDO regions, respectively four producers of Queijo de Azeitão, nine from Queijo de Évora, and 15 from Queijo de Serpa. The interviews were conducted personally by the researchers involved in the project. The firms were identified in the SABI database (Sistema de Análise de Balanços Ibéricos) which allowed us to identify firms dedicated to the production of cheese in the region. From that database we also retrieved accounting data from the firms which will be used to perform an analysis of the possible economic impact of the newly proposed ripening chamber. This information is then compared with the results of the prototype, to identify the advantages of its use.

The prototype that was built consists of a chamber with the following dimensions: $276 \mathrm{~cm}$ of length, $440 \mathrm{~cm}$ of width, and $232 \mathrm{~cm}$ of height. The volume inside the ripening room was divided 
in three different zones, working independently and with the capacity to adjust its own operation depending on the quantity and distribution of the cheese at any moment. The architecture of the data collection and control system is represented in Figure 1.

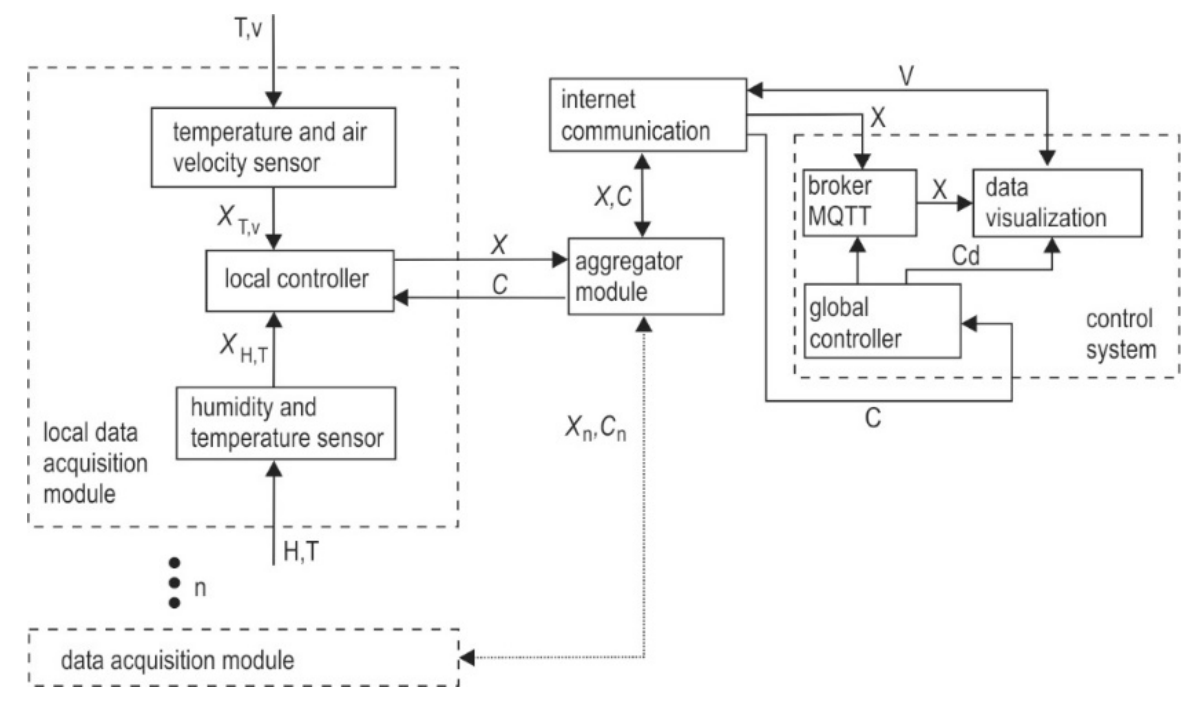

Figure 1. System block diagram of data acquisition and instrumentation apparatus.

The architecture follows a general IoT (Internet of Things) approach. This prototype includes $(n=3)$ portable modules, placed in different locations inside the ripening room, and an aggregator module that collects the data recorded by the local modules every $30 \mathrm{~min}$, transmitting it afterwards to a cloud-based system for recording and processing. Each local module includes sensors for the cheese presence detection, temperature, humidity, $H, T$ (DHT22/AM2302), and $X_{H, T}$ output, temperature and air velocity input, $T, v\left(\mathrm{~F} 660\right.$, DegreeC) and $X_{T, v}$ output, that are connected to a WiPy 3.0 computer hardware platform (PyCom). A flow-rate sensor (YF-S201, Uruk) was placed in the inlet pipe of the humidifier and current transformers were also placed in the power line of the air compressor, refrigeration gas compressor, and exhaust fan (SCT-013, YHDC). The aggregator module is a Raspberry $\mathrm{Pi} 3+$ board with the Raspbian operating system and is remotely controlled. The data module sends the information, $X$, to the aggregator module and receives input control, $C$. The MQTT (message queueing telemetry transport) Internet protocol [21] was used for transmitting the data from local modules to a remote control system. This is used for general control and visualization data, $V$.

The consumption of water was estimated based on the instant flowrate (in $\mathrm{ml} / \mathrm{s})$, recorded by the aggregator module, multiplied by time (s). The consumption of energy was estimated based on the electric voltage, number of phases, and instant current value (A), recorded by the aggregator module, multiplied by time (s).

For the realization of the operation tests, the conditions presented were the following: $11.9^{\circ} \mathrm{C}$ and $83.2 \%$ humidity in the pre-project essay, and $13.5{ }^{\circ} \mathrm{C}$ and $84 \%$ humidity in the post-project essay, which are the averages of the three zones.

Building the whole automation system of an already existent ripening chamber costs about $6605 €$ (plus taxes): $4000 €$ for the automation equipment, $2000 €$ for tubes and accessories, and $605 €$ to pay for the workers which should assemble the systems. These costs were based on the actual market prices for the acquisition of electronic components, plastic pipes, valves, software licenses, and hand labor for assembling and programming the system. When performing the analysis, we will pay attention to the $6605 €$ corresponding to the difference between the existence, or not, of automation in the system, which is the relevant issue of our study.

This is one of the inputs of the analysis of economic viability of the new prototype. For this analysis, we considered as a reference the average results of firms of the sector, showing that this 
process ensures an increase of the competitiveness of small and medium-sized enterprises (SMEs) in the sector, but could also have a high impact on the sector as whole. Moreover, the reduction of consumption of resources like water and electricity, apart from implying a reduction in costs, are also relevant for the environment, helping to attain higher sustainability levels.

\section{Results}

In this section we will identify a set of important economic variables about the prototype, namely the respective production and operational costs. After that, we will identify some potential benefits and, based on some assumptions, we present the potential economic impact of the project in the regions under analysis.

Using the questionnaire, we could identify the main characteristics of the firms in the regions under analysis. Most of the firms are micro or small firms, with familiar structure and mostly oriented to local or regional markets, employing a reduced number of workers (about $92 \%$ have less than 10 workers). Most of the firms report that the electricity costs are very relevant, with about $32 \%$ identifying costs over $1000 €$ per month with water having also a relevant weight (about $300 €$ per month). Regarding the produced cheese, about one third of the firms produce certified cheeses arguing that the cost of the certification is high, associated with the needed bureaucracy.

From the different essays, it was possible to find several important impacts in the consumption of electricity and water, associated to the normal operation of the prototype. The results are described in Table 1 and allow us to conclude that the savings, considering the operation of the prototype, are about $26.44 \%$ in water and about $47.21 \%$ in electricity. Moreover, we developed some statistical tests to confirm the statistical significance of the differences. For the conventional ripening chamber we retrieved data for eight days, and for the automated ripening chamber, 23 days. After the analysis of the normality of the variables, we reject the null hypothesis for the averages of the electric consumption of the compressor, while the averages of the consumptions of the humidifier (both for water and electricity) reveal normal data. We proceeded with the analysis of the equality of the variables. In the case of the non-normal data we used the Mann-Whitney test for the equality of the medians while in the case of normal data we used the t-test for the equality of means.

Table 1. Consumptions of the system with and without automation (the values correspond to the average levels of the essays).

\begin{tabular}{cccc}
\hline & Electricity & Water \\
\hline Conventional ripening chamber & $\begin{array}{c}\text { Refrigeration } \\
\text { Compressor (kWh) }\end{array}$ & Humidificator (kWh) & Humidificator (liters) \\
$\quad$ KS normality test & 11.85 & 8.71 & 11.66 \\
Automated ripening chamber & $0.360^{* *}$ & 0.190 & 0.200 \\
$\quad$ Average & 6.96 & 3.90 & 8.58 \\
KS normality test & $0.174^{*}$ & 0.093 & 0.112 \\
\% of reduction & $41.3^{*}$ & $55.2^{*}$ & $26.4^{*}$ \\
H0: Conventional = Automated & $-2.754^{* * *}$ & $4.075^{* * *}$ & $5.424^{* * *}$ \\
\hline
\end{tabular}

Note: KS normality test refers to the statistical test of Kolmogorov-Smirnov. ${ }^{* * *}$, ${ }^{* *}$, and ${ }^{*}$ denote significance at $1 \%$, $5 \%$, and $10 \%$ levels, respectively.

It is important to note that the savings identified in Table 1 do not correspond to the total of savings in the costs with those two important external services. In fact, $47 \%$ of the savings in electricity corresponds to the reduction of the consumption of the prototype and not the total of the firm. The whole essay had a duration of 21,705 min, during which the compressor worked for 4263, about $19.6 \%$ of the time, implying a potential energetic gain of $9.21 \%$ for the firms. Nevertheless, we consider a $9.21 \%$ reduction to be a significant value.

Regarding water saving, the prototype considers a reduction of about $26 \%$ of its consumption. The final impact is more reduced, not only due to the cost of this resource, but also because the 
amount of water used in the chambers is residual when compared with the total amount of water used in the whole firm, since most of the water, according to the managers, is used in the washing of the cheeses and the clothing used in the firms. Considering that water is a crucial resource for human beings-even more so in the regions where the study was conducted which often suffer from droughts-all the savings are relevant to pursue objectives of attaining sustainable development, even if the monetary costs are less relevant.

Previous identified elements were considered in the economic analysis of the new prototype, considering the possibility of its introduction in each cheese producing firm in the regions under analysis. To assess the economic viability of the prototype, we used the information obtained in the estimations which were already identified. For the investment value, we considered the costs with the automation of the chambers of $6605 €$ per chamber. Regarding the reference annual electricity value used in the study, it was obtained through the average amount of electricity spent by the companies studied. This means an annual reference value of $11,544.14 €$, corresponding $9 \%$ of savings to a decrease in this cost item of $1038.97 €$. We considered the income tax for firms of $21 \%$, which is the actual tax rate in Portugal. For depreciation rates, we considered the value of $25 \%$, consistent with a period of four years as the one to determine the potential economic value to be created with the investment. The total cash flow in Table 2 is the sum of the savings in the electricity cost (deducted from the $21 \%$ of the tax rate once it results in an increase in profits) with the value of the depreciations. Finally, in order to determine the net present value (NPV) of the project, we considered a discount rate of $6 \%$, based on the average return rate on the assets of studied companies and retrieved from the database. It is intended, therefore, to ensure that the implementation of the ripening chambers provides investors with at least the same remuneration that most companies operating in the industry currently create. More details about the calculation of the NPV could be found, for example, in [22].

Table 2. Cash flows of the project.

\begin{tabular}{ccccc}
\hline Item & $\mathbf{2 0 2 1}$ & $\mathbf{2 0 2 2}$ & $\mathbf{2 0 2 3}$ & $\mathbf{2 0 2 4}$ \\
\hline Investment & $13,210.00 €$ & & & \\
Reduction of electricity & $1038.97 €$ & $1038.97 €$ & $1038.97 €$ & $1038.97 €$ \\
Depreciations & $3302.50 €$ & $3302.50 €$ & $3302.50 €$ & $3302.50 €$ \\
Total cash flow & $-9086.71 €$ & $4123.29 €$ & $4123.29 €$ & $4123.29 €$ \\
\hline
\end{tabular}

The cash flows of the project, using the previous information, are the ones presented in Table 2. Considering the discount rate, and that the investment is made immediately at the beginning of 2021, the NPV is equal to $1825.37 €$, meaning that, on average, the project has the potential to release funds over the useful life of the ripening chambers, showing the capacity to cover initial investments and to generate return to investors, considering an annual remuneration of $6 \%$.

\section{Concluding Remarks}

In this paper, we intend to show the economic viability of the investment in the automation of ripening chambers in firms. This automation has the main objective of increasing the productive efficiency of firms, in three different PDO regions in south Portugal and in the firms producing each of the three cheese types under study, in a universe of less than 50 firms. Based on the answers of questionnaires obtained directly from the firms and on the retrieval of data from a database, we could identify the average characteristics of the firms.

To pursue our objective, a ripening chamber was built and several essays were made which allowed us to verify, through tests related to the operation of the developed prototypes, that the new ripening chambers contribute to a reduction in energy consumption in the ripening process of more than $40 \%$, meaning a saving in electricity costs of about $9 \%$. Regarding the consumption of water, the savings of the prototype reach levels of about $26 \%$.

Using the information of the savings in the electricity and the information of the investment and the respective depreciations, it appears that the ripening chamber implementation project is 
economically viable and may contribute to a greater financial sustainability for cheese production companies, increasing not only the competitiveness of the firms individually (most of them SME), but also the sector as a whole. This is crucial information for managers and potential investors, but also for the economic authorities which could have, in this kind of traditional sector, a good basis for enhancement of the economic development of their regions.

Moreover, the results also show that the project could promote not only an increase in the economic indicators but also help in the increase of sustainable use of some resources like electricity and water, also contributing to environmental sustainability.

It is important to note that in the economic analysis, we just considered the values that we estimated during the essays. However, other benefits could arise from the implementation of the prototype in the firms. As the productive efficiency increases, it is expected that firms could increase their sales, once they produce more cheese with higher quality using the same raw materials. This happens because the prototype would allow for higher efficiency levels in the production, increasing the quality of the cheeses which contributes for a higher quantity of final available product. As the prototype has a direct impact in the ripening conditions of the cheeses, it will enhance the quantity of final product and the necessary quality for the introduction in the market, optimizing the relationship between the inputs of the activity and the generated outputs. On the other hand, and as firms have higher quantities for sale, it could contribute to greater financial sustainability which would allow businesses to be more solid and possibly gain the necessary conditions to obtain the certification of their products, increasing the margins, since firms could practice higher prices. Another possible relevant impact is the stock reduction promoted by the prototype, which could also have a positive impact in the results of the firms.

At this point, it is relevant to identify some limitations of this study. Firstly, the analysis is made for a reduced number of firms, because the study is related with the above-mentioned project, which was limited to the analysis of cheeses in three different regions. Nevertheless, the results are promising regarding the economic potential of the prototype. Another possible limitation is the fact that we do not consider estimations for some relevant parameters in the economic analysis. It is in the objectives of the research team in future research to make those estimations, allowing for a deeper economic analysis of the impact of the prototype and also for understanding the impact on the sector as a whole. Although it is noticeable that the prototype seems to have economic viability even considering just the considered parameters, meaning that the inclusion of other benefits should increase that viability.

In the future, a multidisciplinary study should be performed to evaluate the impact on the physicochemical, microbiological, and sensorial properties of ewe's cheese ripened in the prototype, compared with the standard ripening chambers in the regions under study. Moreover, the distribution of air inside the prototype should also be studied, using computational fluid dynamics, in order to homogenize the environmental conditions like temperature, humidity, and air velocity, minimizing the operational costs and continuing to improve the competitiveness of the businesses.

Author Contributions: Conceptualization, N.T., M.C.P., P.F., G.P.C., R.S., F.M.R., J.D., J.C.M., and J.J.C.; formal analysis: N.T., M.C.P., P.F., G.P.C., R.S., F.M.R., J.D., J.C.M., and J.J.C.; methodology: N.T., M.C.P., P.F., G.P.C., R.S., F.M.R., J.D., J.C.M., and J.J.C.; writing-original draft: N.T., M.C.P., P.F., G.P.C., R.S., F.M.R., J.D., J.C.M., and J.J.C.; writing-review and editing: N.T., M.C.P., P.F., G.P.C., R.S., F.M.R., J.D., J.C.M., and J.J.C. All authors have read and agreed to the published version of the manuscript.

Funding: The authors thank to: (i) FEDER, through the Programa Operacional Regional de Lisboa and Programa Operacional Regional do Alentejo and Fundação para a Ciência e Tecnologia for their financial support to "CFD4CHEESE-Application of computational fluid mechanics in the optimization of ripening conditions of traditional cheeses" (ALT20-03-0145-FEDER-023356); (ii) João Dias acknowledges the financial support of Fundação para a Ciência e a Tecnologia (grant UIDP/04035/2020); (iii) Rute Santos and Paulo Ferreira also acknowledge the financial support of Fundação para a Ciência e a Tecnologia (grant UIDB/05064/2020).

Conflicts of Interest: The authors declare no conflict of interest. 


\section{References}

1. Rodrigues, L.; Machado, M.; Pinheiro, C. Cheese: Food perception and food choice. Recent Pat. Food Nutr. Agric. 2018, 9, 104-110. [CrossRef] [PubMed]

2. Fox, P.; McSweeney, P. Cheese: An Overview. In Cheese: Chemistry, Physics and Microbiology, 4th ed.; McSweeney, P.L.H., Fox, P., Cotter, P.D., Everett, D.W., Eds.; Elsevier Academic Press: London, UK, 2017; Volume 1, pp. 5-21.

3. Nybakk, E.; Jenssen, J. Innovation Strategy, Working Climate, and Financial Performance in Traditional Manufacturing Firms: An Empirical Analysis. Int. J. Innov. Manag. 2012, 16, 1250008. [CrossRef]

4. Aziz, F.; Samsudin, S.; Nambiar, N.; Aziz, U.; Li, E.; Zhong, R. Industry 4.0 in New Zealand dairy industry. Int. J. Agil. Syst. Manag. 2019, 12, 180-197. [CrossRef]

5. Ragkos, A.; Theodoridis, A.; Fachouridis, A.; Batzios, C. Dairy Farmers' Strategies against the Crisis and the Economic Performance of Farms. Procedia Econ. Financ. 2015, 33, 518-527. [CrossRef]

6. Sauer, J.; Latacz-Lohmann, U. Investment, technical change and efficiency: Empirical evidence from German dairy production. Eur. Rev. Agric. Econ. 2015, 42, 151-175. [CrossRef]

7. Barać, Z.; Muminović, S. The impact of capital investments on dairy processing industry features: Evidence from Slovenia, Croatia and Serbia. Mljekarstvo 2013, 63, 140-149.

8. González-García, S.; Castanheira, É.; Dias, A.; Arroja, L. Environmental performance of a Portuguese mature cheese-making dairy mill. J. Clean. Prod. 2013, 41, 65-73. [CrossRef]

9. Valta, K.; Damala, P.; Angeli, E.; Antonopoulou, G.; Malamis, D.; Haralambous, K. Current Treatment Technologies of Cheese Whey and Wastewater by Greek Cheese Manufacturing Units and Potential Valorisation Opportunities. Waste Biomass Valoriz. 2017, 8, 1649-1663. [CrossRef]

10. Alves, O.; Brito, P.; Lopes, P.; Reis, P. Optimization of Energy Consumption in Cold Chambers in the Dairy Industry. Energy Procedia 2014, 50, 494-503. [CrossRef]

11. Sellers-Rubio, R.; Más-Ruiz, F. Economic efficiency of members of protected designations of origin: Sharing reputation indicators in the experience goods of wine and cheese. Rev. Manag. Sci. 2015, 9, 175-196. [CrossRef]

12. Vakoufaris, H. The impact of Ladotyri Mytilinis PDO cheese on the rural development of Lesvos island, Greece. Local Environ. 2010, 15, 27-41. [CrossRef]

13. O'Sullivan, O.; Cotter, P.D. Microbiota of raw milk and raw milk cheeses. In Cheese: Chemistry, Physics and Microbiology, 4th ed.; McSweeney, P.L.H., Fox, P., Cotter, P.D., Everett, D.W., Eds.; Elsevier Academic Press: London, UK, 2017; Volume 1, pp. 301-316.

14. Alvarenga, N.; Canada, J.; Sousa, I. Effect of freezing on the rheological, chemical and colour properties of Serpa cheese. J. Dairy Res. 2011, 78, 80-87. [CrossRef] [PubMed]

15. Leclercq-Perlat, M.; Sicard, M.; Trelea, I.; Picque, D.; Corrieu, G. Temperature and relative humidity influence the microbial and physicochemical characteristics of Camembert-type cheese ripening. J. Dairy Sci. 2012, 95, 4666-4682. [CrossRef] [PubMed]

16. Macedo, A.; Malcata, F.; Oliveira, J. Effect of production factors and ripening conditions on the characteristics of Serra cheese. Int. J. Food Sci. Technol. 1997, 32, 501-511. [CrossRef]

17. Baudrit, C.; Hélias, A.; Perrot, N. Joint treatment of imprecision and variability in food engineering: Application to cheese mass loss during ripening. J. Food Eng. 2009, 93, 284-292. [CrossRef]

18. Roteiros e Eventos. 2015. Available online: https://roteiroseeventos.wordpress.com/2015/10/19/a-rota-dosqueijos-de-portugal-conheca-alguns-dos-melhores-quijos-do-mundo/ (accessed on 20 July 2020).

19. Cabo, P.; Matos, A.; Fernandes, A.; Ribeiro, M. Evolução da produção e comercialização de produtos tradicionais qualificados de ovinos e caprinos (2003-2012). Revista de Ciências Agrárias 2017, 40, 329-344. [CrossRef]

20. Central de Balanços do Banco de Portugal. Available online: https://www.bportugal.pt/page/central-debalancos (accessed on 20 July 2020).

21. Hillar, G. MQTT Essentials—A Lightweight IoT Protocol; Packt Publishing Ltd.: Birmingham, UK, 2017.

22. Ross, S.; Westerfield, R.; Jordan, B. Essentials of Corporate Finance, 9th ed.; McGraw-Hill: New York, NY, USA, 2017. 